\title{
A importância da paramentação e desparamentação seguras em infecções por aerossol, com foco à Covid-19: uma revisão da literatura
}

\author{
The importance of dressing and undressing safely in aerosol infections, with a focus on \\ Covid-19: a literature review
}

\section{La importancia de pornese y quitarse de manera segura en las infecciones por aerosoles, con un enfoque en Covid-19: una revisión de la literatura}

Amanda Kelly Teixeira Soares ${ }^{1 *}$, Fabiane Roriz Arruda ${ }^{1}$, Gislane Martins de Melo Leal Novais ${ }^{1}$, Rosenir Barros Martins ${ }^{1}$, Andrey Hudson Interaminense Mendes de Araújo'.

\section{RESUMO}

Objetivo: Avaliar a partir de produções bibliográficas recentes a importância da paramentação e desparamentação de equipamentos de proteção individual com foco principalmente em infecções por aerossol e dando destaque a recente infecção por coronavírus. Métodos: Trata-se de uma revisão integrativa da literatura, com abordagem qualitativa. Às pesquisas dos artigos foram feitas nas bases de dados SCIELO, PUBMED e BVS. Os critérios de inclusão foram de artigos disponíveis publicados em português, inglês e espanhol, artigos originais na íntegra; e os critérios de exclusão foram artigos desatualizados, textos incompletos que não contenham dados com o objetivo proposto e fora do recorte temporal. Resultados: O estudo permitiu refletir sobre a discussão nas seguintes categorias: fatores de risco de contaminação ao profissional de saúde ao cuidar de pacientes com corona vírus, procedimentos geradores de aerossóis por COVID-19 e medidas de precaução em relação à COVID-19 na paramentação, desparamentação e descarte correto de EPI's. Considerações finais: Diante as repercussões da covid-19 são necessárias orientações aos profissionais de saúde com conhecimento teórico e treinamentos práticos na paramentação, desparamentação e descarte seguros de EPI's, levando em conta procedimentos geradores de aerossol.

Palavras-chave: Contaminação de equipamentos, Equipamentos de proteção individual, Aerossóis, Infecção por coronavírus.

\section{ABSTRACT}

Objective: Evaluate, based on recent bibliographic productions, the importance of dressing and undressing personal protective Equipment, focusing mainly on aerosol infections and highlighting the recent corona virus infection. Methods: It is an integrative literature review with a qualitative approach. The searches of the articles were carried out in the SCIELO, PUBMED, and VHL databases. Inclusion criteria were available original articles, in full, published in Portuguese, English, and Spanish; and the exclusion criteria were outdated articles, incomplete texts that do not contain data with the proposed objective and outside the time frame. Results: The study made it possible to reflect on the discussion in the following categories: risk factors for contamination to health professionals when caring for patients with coronavirus, aerosolgenerating procedures by COVID-19, and preventive measures concerning COVID-19 in dressing, undressing, and correct disposal of PPE's. Final considerations: Given the repercussions of covid-19 it is necessary to guide health professionals with theoretical knowledge and practical training in the dressing, undressing, and safe disposal of PPE's, taking into account aerosol-generating procedures.

Keywords: Contamination of equipment, Personal protective equipment, Aerosols, Infection from coronavirus.

\section{RESUMEN}

Objetivo: Evaluar, en base a producciones bibliográficas recientes, la importancia de pornese y quitarse el equipo de protección personal, enfocándose principalmente en las infecciones por aerosoles y destacando la reciente infección por coronavirus. Métodos: Es una revisión integradora de la literatura con un enfoque cualitativo. Las búsquedas de los artículos se realizaron en las bases de datos SCIELO, PUBMED y BVS. Los criterios de inclusión fueron artículos originales disponibles, en su totalidad, publicados en portugués, inglés y español; y los criterios de exclusión fueron artículos desactualizados, textos incompletos que no contienen datos con el objetivo propuesto y fuera del marco temporal. Resultados: El estudio permitió reflexionar sobre la discusión en las siguientes categorías: factores de riesgo de contaminación a los profesionales de la salud en la atención de pacientes con coronavirus, procedimientos generadores de aerosoles por COVID-19 y medidas preventivas sobre COVID-19 en el vendaje, desvestirse y desechar correctamente Ios EPP. Consideraciones finales: Dadas las repercusiones del covid-19, que es necesario orientar a los profesionales de la salud con conocimientos teóricos y formación práctica en el vestuario, desvestimiento y disposición segura de los EPP, teniendo en cuenta los procedimientos generadores de aerosoles.

Palabras clave: Contaminación de equipos, Equipos de protección personal, Aerosoles, Infección por coronavirus.

${ }^{1}$ Universidade Paulista (UNIP), Brasília - DF. *E-mail: amandasooaresk@gmail.com 


\section{INTRODUÇÃO}

As partículas por aerossóis são capazes de se manter em suspensão no ar, percorrendo vários metros e permanecendo por horas, sendo eliminadas durante a respiração, fala, tosse ou espirro. Desse modo, a transmissão por aerossol ocorre quando uma pessoa infectada produz partículas infecciosas, pois o agente patogênico fica circulando no ar por algumas horas e os tecidos-alvo nos quais o patógeno inicia a infecção podem ser alcançados pelo aerossol. Protocolos suscetíveis de transmitir aerossóis, tais como a VNI (ventilação não invasiva), intubação, cânula nasal de alto fluxo, bolsa ventilação por máscara são os que têm grandes riscos. Sendo assim, o problema das infecções por essas partículas ocorre pelas vias aéreas, a depender do hospedeiro e de fatores ambientais, podendo estes desenvolver infecções graves (STRUYF T, et al., 2020).

A COVID-19 é uma doença viral aguda causada pelo vírus SARS-CoV-2 (síndrome respiratória aguda grave coronavírus 2), no qual a infecção respiratória pode variar de grau leves a graves, capaz de ser assintomática ou oligo sintomático. Para se chegar a um diagnóstico é preciso identificar os sintomas e sinais, analisar as amostras laboratoriais de nariz e garganta ou exames de imagem do tórax, como tomografias computadorizadas (ATZARODT CL, et al., 2020).

No começo do ano de 2020 foi determinado que o SARS-CoV-2 possui dois principais sintomas, que são a saturação baixa de oxigênio e febres, chegando ao caso de ter que usar Ventilação Mecânica (VM) para suprir os baixos níveis de oxigênio. Assim, os sintomas mais comuns são tosse, dor de garganta, coriza, temperatura alta, diarreia, dor de cabeça, dores musculares ou articulares, fadiga e perda do olfato e paladar (SOMMERSTEIN R, et al., 2020).

Os centros de controle e prevenção de doenças (CDC) passaram a pressupor que o meio de transmissão entre os indivíduos do SARS-CoV-2 se dá, sobretudo, por meio de partículas respiratórias ou por meio de contato com áreas contaminadas. É importante destacar que nas áreas de grande risco de contaminações, como por exemplo as áreas do âmbito hospitalar, o conhecimento de como se dá a transmissão do vírus e como combater a infecção por meio de cuidados apropriados são muito importantes para a diminuição das infecções, assim como a importância da paramentação e desparamentação dos Equipamentos de Proteção Individuais (EPIs) de forma segura, com o intuito de reduzir o quadro de profissionais afastados e infectados por COVID-19. Nesse contexto, o problema no caso de COVID-19 decorre de reduzir a disseminação do vírus entre os profissionais de saúde e na sociedade (MARQUES LC, et al., 2020).

O EPI deve ser utilizado ao considerar as precauções padrão recomendadas para a pandemia, bem como precaução de contato, por gotículas e aerossol. Para tanto, é importante investir no conhecimento, qualificação e treinamento dos profissionais de saúde para o uso adequado desses equipamentos no manejo e cuidado. Paramentação e desparamentação seguras e adequadas de roupas são formas eficazes de evitar a contaminação por profissionais de saúde (MACHADO WCA, et al., 2020; KIM UJ, et al., 2020).

Tal conhecimento é fundamental para identificar que os meios de precauções padrões devem permanecer a todos os enfermos, ainda que assintomáticos, sendo relevante o uso de regulamentos de biossegurança e a utilização de EPIs no combate dos números de contaminações nos momentos de atendimentos em meios hospitalares. Assim, é do saber mundial que profissionais da área da saúde que tratam de enfermos infectados com a SARS-CoV-2 correm grande risco de se contaminar com a doença (ARAÚJO BCL, et al., 2020; MORRELL ALG, et al., 2020).

Os profissionais de enfermagem que atuam na linha de frente de COVID-19 têm um grande potencial de serem contaminados devido à exibição à carga viral, o uso inadequado de EPIs, realização incorreta da higienização das mãos, descarte do material no local incorreto e a falta de treinamentos, englobando a paramentação e desparamentação. Diante desses fatores, os trabalhadores da área da saúde caracterizam entre $4 \%$ e $12 \%$ dos infectados. Até o momento, o Brasil já registrou mais de 4,1 mil profissionais de enfermagem contaminados e 108 óbitos dentre estes (MARQUES LC, et al., 2020). A taxa de letalidade e mortalidade da COVID-19 diversificou entre países e regiões em decorrência da escassez de recursos e estruturas de serviços de saúde e de vigilância, ações, rotinas, suprimentos e disponibilidade e capacidade de realização dos testes (OLIVEIRA HC, et al., 2020). 
Este trabalho teve como objetivo avaliar, a partir de produções bibliográficas recentes, a importância da paramentação e desparamentação seguras em infecções por aerossol e dando destaque a recente infecção por coronavírus entre os profissionais da área da saúde.

\section{MÉTODOS}

Trata-se de uma revisão integrativa de literatura, com abordagem qualitativa, que pretende fazer o levantamento de informações com base na problemática exposta, possibilitando agregar conhecimento a enfermagem e outros profissionais da área da saúde sobre paramentação e desparamentação de EPIs com foco principalmente em infecções por aerossol e dando destaque a recente infecção por COVID-19.

Na presente pesquisa, construiu-se uma estratégia de busca de descritores no Descritores em Ciências da Saúde (Decs), no Medical Subject Headings (MESH) escolha de palavras-chave, sendo utilizados o operador booleano "AND" e os descritores: contaminação de equipamentos, equipamentos de proteção individual, aerossóis e infecção por coronavírus. A pesquisa dos artigos foi feita nas bases de dados de âmbito nacional e internacional, que são as seguintes: Scientific Eletronic Library Online (SCIELO), a United State National Library of Medicine (PUBMED) e na Biblioteca Virtual de Saúde (BVS).

Os critérios adotados para inclusão dos artigos foram textos completos publicados em língua portuguesa, inglês e espanhol, artigos originais e na íntegra online, atualizados no período de 2016 até março de 2021; artigos gratuitos, estudos no formato de artigos originais oriundos de produção científica. Os critérios de exclusão foram: publicações desatualizadas, publicações anteriores a 2016, textos incompletos que não contenham dados de pesquisa relevantes ou não se relaciona com o tema tratado e fora do recorte temporal, especificamente (Figura 1).

Estabeleceu-se, para avaliação e análise dos dados encontrados, um mecanismo para fornecer informações dos estudos, com o intuito de integrar dados e características para compor a pesquisa de revisão. Foram coletadas variáveis de identificação, tais como: título, autor, objetivos, métodos, conclusão e ano de publicação.

Figura 1 - Fluxograma de busca e seleção dos artigos para revisão integrativa sobre a importância da paramentação e desparamentação seguras em infecções por aerossol com foco à COVID-19.

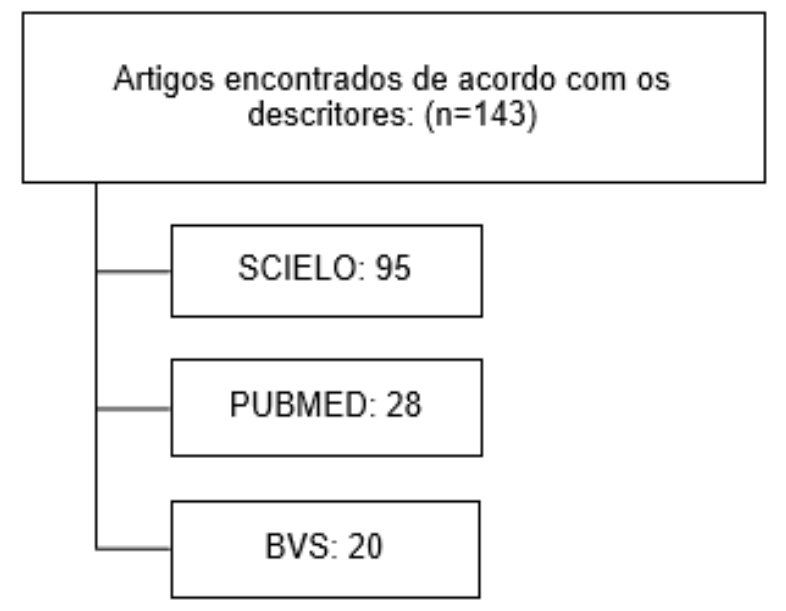

Excluídos após a leitura dos títulos e resumos por não consideraram os critérios de inclusão: ( $\mathrm{n}=107$ )

Fonte: Soares AKT, et al.,2021.

\section{RESULTADOS}

No Quadro 1, encontram-se as informações a respeito dos 20 artigos contidos nesta revisão integrativa. Foram sintetizados e interpretados todos os resultados por meio de uma comparação dos dados evidenciados na análise dos artigos. 
Quadro 1 - Distribuição dos artigos de acordo com o título, autores, objetivo, método, conclusão e ano de publicação.

\begin{tabular}{|c|c|c|c|c|c|}
\hline № & Título & Autores, Ano & Objetivo & Métodos & Conclusão \\
\hline$\tau$ & $\begin{array}{l}\text { Avaliação e gestão de risco entre } \\
\text { enfermeiros da linha de frente no } \\
\text { contexto do vírus COVID-19 na região } \\
\text { norte do Reino da Arabia Saudita }\end{array}$ & $\begin{array}{l}\text { Albaqawi HM, } \\
\text { et al., } 2021\end{array}$ & $\begin{array}{l}\text { Este estudo avaliou o risco após o } \\
\text { contato de enfermeiros que presta } \\
\text { assistência aos pacientes com } \\
\text { diagnóstico de COVID-19. }\end{array}$ & $\begin{array}{l}\text { Estudo descritivo, com abordagem } \\
\text { quantitativa, realizado com enfermeiras na } \\
\text { linha da frente da COVID-19 na parte norte da } \\
\text { Arábia Saudita, utilizando um questionário } \\
\text { auto aplicado em um formulário do Google. }\end{array}$ & $\begin{array}{l}\text { Conclui-se que práticas necessitam ser } \\
\text { melhoradas no combate a esse vírus, precisa- } \\
\text { se que os enfermeiros líderes estabeleçam um } \\
\text { sistema de controle de infecção que oferte } \\
\text { monitoramento em momento real. }\end{array}$ \\
\hline$\sim$ & $\begin{array}{l}\text { Fatores que afetam o comprometimento } \\
\text { profissional dos enfermeiros durante a } \\
\text { pandemia do COVID-19: um estudo } \\
\text { transversal }\end{array}$ & $\begin{array}{l}\text { Duran S, et al., } \\
2021\end{array}$ & $\begin{array}{l}\text { Analisar os fatores que afetam o } \\
\text { compromisso profissional dos } \\
\text { enfermeiros durante a pandemia do } \\
\text { COVID - } 19 \text {. }\end{array}$ & $\begin{array}{l}\text { Estudo transversal, realizado com } 389 \\
\text { enfermeiras de um hospital estadual turco. }\end{array}$ & $\begin{array}{l}\text { Evidenciam-se que o estudo com base nos } \\
\text { resultados foi destinado para hospitais e } \\
\text { gerentes de enfermagem para manter e } \\
\text { aumentar o compromisso profissional dos } \\
\text { enfermeiros. }\end{array}$ \\
\hline$m$ & \begin{tabular}{|l} 
Experiências de enfermeiras \\
despachadas em usar equipamento de \\
proteção individual completos para \\
cuidar de pacientes com COVID - 19 na \\
China - um estudo qualitativo descritivo \\
\end{tabular} & $\begin{array}{l}\text { Chen F, et al., } \\
2021\end{array}$ & $\begin{array}{l}\text { Identificadas as experiências de } \\
\text { enfermeiras despachadas com o } \\
\text { uso de equipamento de proteção } \\
\text { individual para tratar de pacientes } \\
\text { com COVID-19 em Wuhan, China. } \\
\end{array}$ & $\begin{array}{l}\text { Estudo descritivo, com abordagem qualitativo, } \\
\text { realizadas entrevistas telefônicas em uma } \\
\text { amostra intencional de } 15 \text { enfermeiros da } \\
\text { linha de frente, em um surto de março a abril } \\
\text { de } 2020 \text {. }\end{array}$ & $\begin{array}{l}\text { Conclui-se que em um período de } 40 \text { dias os } \\
\text { enfermeiros da linha de frente confrontaram } \\
\text { desafios, referente ao uso de equipamento de } \\
\text { proteção individual ao cuidar de pacientes com } \\
\text { COVID-19. }\end{array}$ \\
\hline$\nabla$ & $\begin{array}{l}\text { Dispositivos de barreiras, intubação e } \\
\text { estratégias de mitigação de aerossol: } \\
\text { Équipamentos de proteção pessoal na } \\
\text { época da doença do coronavírus } 2019\end{array}$ & $\begin{array}{l}\text { Fried EA, et al., } \\
2021\end{array}$ & $\begin{array}{l}\text { Analisar o impacto na proliferação } \\
\text { de gotículas e aerossóis, que } \\
\text { contribuem para a transmissão da } \\
\text { COVID-19. }\end{array}$ & $\begin{array}{l}\text { Estudo desenvolvido com base em dois } \\
\text { dispositivos de barreira, uma caixa de } \\
\text { intubação e uma folha de intubação de } \\
\text { plástico transparente. Os dados coletados por } \\
\text { flash de alta velocidade, aerossol e dispersão } \\
\text { de gotículas foram avaliados } \\
\text { qualitativamente. }\end{array}$ & $\begin{array}{l}\text { Conclui-se que as caixas e folhas de intubação } \\
\text { podem diminuir a exposição dos profissionais } \\
\text { de saúde às gotículas, porém podem ser } \\
\text { redirecionadas as partículas aerossolizadas, } \\
\text { com maior exposição a aerossóis. }\end{array}$ \\
\hline 10 & $\begin{array}{l}\text { Risco de aquisição do COVID-19 entre a } \\
\text { equipe de enfermagem da UTI com o uso } \\
\text { de procedimentos respiratórios } \\
\text { geradores de aerossol conduzido pelo } \\
\text { paciente e o uso ideal de equipamentos } \\
\text { de proteção individual (EPI) }\end{array}$ & $\begin{array}{l}\text { Lormans } P \text {, et } \\
\text { al., } 2021\end{array}$ & $\begin{array}{l}\text { Conhecer a proteção adequada do } \\
\text { profissional de saúde recomendada } \\
\text { para garantir sua segurança. }\end{array}$ & $\begin{array}{l}\text { Estudo de coorte observacional, avaliamos o } \\
\text { risco de abandono da equipe de enfermagem } \\
\text { da UTI relacionado ao COVID-19 em relação } \\
\text { à exposição ocupacional a pacientes do } \\
\text { CoVID-19. }\end{array}$ & $\begin{array}{l}\text { Conclui-se que não foi encontrando risco } \\
\text { aumentado de transmissão, apesar do uso } \\
\text { liberal de procedimentos geradores de } \\
\text { aerossol na presença de EPI. }\end{array}$ \\
\hline 0 & $\begin{array}{l}\text { Segurança dos profissionais de saúde no } \\
\text { enfrentamento do novo coronavírus no } \\
\text { Brasil }\end{array}$ & $\begin{array}{l}\text { Santana } N \text {, et } \\
\text { al., } 2021\end{array}$ & $\begin{array}{l}\text { Expor a quantidade de profissionais } \\
\text { de saúde acometidos pela COVID- } \\
19 \text { no Brasil, identificando medidas } \\
\text { de controle para diminuição da } \\
\text { vulnerabilidade e as repercussões. } \\
\end{array}$ & $\begin{array}{l}\text { Estudo descritivo, usado como fonte, boletins } \\
\text { epidemiológicos e o Centers for Disease } \\
\text { Control and Prevention. }\end{array}$ & $\begin{array}{l}\text { Foram reveladas condições de trabalho } \\
\text { desigual e segregacionista para a saúde a que } \\
\text { os profissionais de saúde estão submetidos, } \\
\text { requer mudanças e reconhecimentos e urge } \\
\text { para a valorização desse grupo profissional. }\end{array}$ \\
\hline$\lambda$ & $\begin{array}{l}\text { Práticas dos profissionais de saúde e } \\
\text { fatores associados em relação às } \\
\text { medidas de precaução para a pandemia } \\
\text { de COVID-19 em unidades de saúde } \\
\text { pública da zona de Gamo, sul da Etiópia: } \\
\text { um estudo transversal }\end{array}$ & $\begin{array}{l}\text { Mersha A, et al., } \\
2021\end{array}$ & $\begin{array}{l}\text { Avaliar a prática do profissional de } \\
\text { saúde e os fatores associados às } \\
\text { medidas de precaução para a } \\
\text { pandemia de COVID-19 em } \\
\text { unidades de saúde pública da zona } \\
\text { do Gamo, sul da Etiópia. }\end{array}$ & $\begin{array}{l}\text { Estudo transversal, realizada com } 428 \\
\text { profissionais de saúde das unidades de saúde } \\
\text { públicas da zona do Gamo, sul da Etiópia. A } \\
\text { amostragem aleatória e os dados coletados } \\
\text { pela ferramenta de pesquisa Open Data Kit. }\end{array}$ & $\begin{array}{l}\text { A magnitude das boas práticas de medidas de } \\
\text { precaução para a pandemia de COVID-19 } \\
\text { entre os profissionais de saúde foi } \\
\text { baixa. Assim, diferentes intervenções para } \\
\text { melhorar o conhecimento e a atitude dos } \\
\text { profissionais de saúde no sistema de saúde } \\
\text { são altamente necessárias para impulsionar a } \\
\text { prática e avançar na prestação de serviços. }\end{array}$ \\
\hline
\end{tabular}




\begin{tabular}{|c|c|c|c|c|c|}
\hline № & Título & Autores, Ano & Objetivo & Métodos & Conclusão \\
\hline$\infty$ & $\begin{array}{l}\text { Detecção de SARS-CoV-2 no ambiente } \\
\text { de saúde: um estudo multicêntrico } \\
\text { conduzido durante a primeira onda do } \\
\text { surto COVID-19 na Inglaterra }\end{array}$ & $\begin{array}{l}\text { Moore G, et al., } \\
2020\end{array}$ & $\begin{array}{l}\text { Avaliar como a síndrome } \\
\text { respiratória aguda grave } \\
\text { coronavírus-2 (SARS-CoV-2) se } \\
\text { dissemina no ambiente hospitalar é } \\
\text { essencial para auxiliar a equipe com } \\
\text { medidas de controle de infecção. } \\
\end{array}$ & $\begin{array}{l}\text { Estudo realizado em oito hospitais na } \\
\text { Inglaterra na primeira onda do surto da } \\
\text { doença coronavírus em 2019. As amostras } \\
\text { analisadas foram usando a reação em cadeia } \\
\text { da polimerase de transcrição reversa (PCR) e } \\
\text { ensaios de isolamento de vírus. }\end{array}$ & $\begin{array}{l}\text { Conclui-se que a limpeza pode diminuir o risco } \\
\text { de transmissão de contato do SARS-CoV-2, } \\
\text { porém, é essencial o uso de equipamentos de } \\
\text { proteção individuais específicos para } \\
\text { procedimentos geradores e não geradores de } \\
\text { aerossol. }\end{array}$ \\
\hline$\sigma$ & $\begin{array}{l}\text { Uso de equipamentos de proteção } \\
\text { individual (EPI) para cuidar de pacientes } \\
\text { com covid-10: revisão de escopo }\end{array}$ & $\begin{array}{l}\text { Garcia GPA, et } \\
\text { al., } 2020\end{array}$ & $\begin{array}{l}\text { Conhecer sobre as orientações para } \\
\text { o uso de equipamentos de proteção } \\
\text { individuais aos profissionais de } \\
\text { saúde ao cuidar de pacientes } \\
\text { suspeitos ou infectados por COVID- } \\
19 .\end{array}$ & $\begin{array}{l}\text { Trata-se de uma revisão de escopo, com } \\
\text { pesquisa de estudos primários, revisões e } \\
\text { pré-impressão de artigos em inglês, } \\
\text { português e espanhol dos últimos anos. }\end{array}$ & $\begin{array}{l}\text { Evidenciam-se que os equipamentos de } \\
\text { proteção individual usados não reconhecem a } \\
\text { padronização de segundo tipo global, } \\
\text { qualidade e fornecimento adequado, expondo } \\
\text { esses profissionais ao risco de contágio. }\end{array}$ \\
\hline 으 & $\begin{array}{l}\text { Uma comparação de gota e } \\
\text { contaminação de contato usando } 3 \\
\text { técnicas de barreiras simulada para } \\
\text { intubação COVID-19: um estudo de } \\
\text { garantia de qualidade }\end{array}$ & $\begin{array}{l}\text { Rose P, et al., } \\
2020\end{array}$ & $\begin{array}{l}\text { Avaliar o risco de contágio por } \\
\text { gotículas, contato e aerossóis para } \\
\text { profissionais de saúde, durante a } \\
\text { intubação de pacientes com COVID- } \\
19 .\end{array}$ & $\begin{array}{l}\text { Estudo de garantia de qualidade, realizadas } \\
\text { intubações em um manequim para simular a } \\
\text { propagação de partículas. No período de } 4 \text { de } \\
\text { abril de } 2020 \text { num hospital acadêmico } \\
\text { terciário em Vancouver, British Columbia, } \\
\text { Canadá. }\end{array}$ & $\begin{array}{l}\text { A utilização de uma folha de plástico no } \\
\text { decorrer de uma intubação de pacientes com } \\
\text { COVID-19 pode crescer o risco de } \\
\text { contaminação por gotículas, contato e } \\
\text { aerossóis, durante a intubação. }\end{array}$ \\
\hline$\mp$ & $\begin{array}{l}\text { COVID-19: Limites na implementação de } \\
\text { equipamentos individual (EPI) } \\
\text { recomendados para profissionais de } \\
\text { saúde }\end{array}$ & $\begin{array}{l}\text { Assunção AA, } \\
\text { et al., } 2020\end{array}$ & $\begin{array}{l}\text { Comparar protocolos nacionais e } \\
\text { estaduais brasileiros sobre como, } \\
\text { quando e quais EPls precisam ser } \\
\text { usados no acolhimento aos } \\
\text { pacientes infectados pelo COVID- } \\
19 .\end{array}$ & $\begin{array}{l}\text { Estudo exploratório de curto período de dois } \\
\text { meses, analisa o reconhecimento do surto } \\
\text { pandêmico da crise sanitária. }\end{array}$ & $\begin{array}{l}\text { Conclui-se que os resultados são dicas para } \\
\text { os protocolos dos profissionais de saúde para } \\
\text { a revisão do novo coronavírus. }\end{array}$ \\
\hline$\stackrel{\sim}{\leftarrow}$ & $\begin{array}{l}\text { Máscaras como equipamento de } \\
\text { proteção individual na pandemia COVID- } \\
\text { 19: como, quando e o que deve ser } \\
\text { usados }\end{array}$ & $\begin{array}{l}\text { Aranaz JMA, et } \\
\text { al., } 2020\end{array}$ & $\begin{array}{l}\text { Resumir as características e } \\
\text { recomendações dos vários tipos de } \\
\text { máscaras, diante a demanda que } \\
\text { cresceu por profissionais de saúde e } \\
\text { pela população em geral. }\end{array}$ & $\begin{array}{l}\text { Estudo de rastreamento, identificadas } \\
\text { recomendações divulgadas pela OMS, o } \\
\text { Centro Europeu de Prevenção de Doenças, o } \\
\text { Centro de Medicina Baseada em Evidências e } \\
\text { o Ministério da Saúde do Governo da } \\
\text { Espanha. }\end{array}$ & $\begin{array}{l}\text { Considerando a carência de equipamentos de } \\
\text { proteção individual devido à pandemia } \\
\text { COVID-19, precisa-se determinar uma } \\
\text { prioridade quanto ao uso de cada tipo de } \\
\text { máscara de acordo com o usuário e a } \\
\text { atividade realizada. }\end{array}$ \\
\hline$\stackrel{m}{-}$ & $\begin{array}{l}\text { O que a pandemia da COVID-19 tem nos } \\
\text { ensinado sobre adoção de medidas de } \\
\text { precaução? }\end{array}$ & $\begin{array}{l}\text { Oliveira AC, et } \\
\text { al., } 2020\end{array}$ & $\begin{array}{l}\text { Explorar a pandemia da COVID-19, } \\
\text { compreender com adoção das } \\
\text { medidas preventivas recomendadas } \\
\text { pela Organização Mundial de Saúde } \\
\text { e com o cenário epidemiológico no } \\
\text { mundo, na América Latina e no } \\
\text { Brasil. }\end{array}$ & $\begin{array}{l}\text { Analisar a pandemia COVID-19 e o que (re) } \\
\text { aprendemos com a experiência global para a } \\
\text { adoção das medidas de prevenção } \\
\text { preconizadas pela Organização Mundial da } \\
\text { Saúde e com o panorama epidemiológico no } \\
\text { mundo, na América Latina e no Brasil. }\end{array}$ & $\begin{array}{l}\text { Conclui-se que essa pandemia é a mais grave } \\
\text { atual da história e pode ser influenciada por } \\
\text { medidas comportamentais individuais e } \\
\text { coletivas. }\end{array}$ \\
\hline$\stackrel{\nabla}{\square}$ & $\begin{array}{l}\text { Protegendo os profissionais de saúde da } \\
\text { infecção subclínica por coronavírus }\end{array}$ & $\begin{array}{l}\text { Chang D, et al., } \\
2020\end{array}$ & $\begin{array}{l}\text { Assegurar a segurança dos } \\
\text { profissionais de saúde não apenas } \\
\text { para proteger o atendimento } \\
\text { constante ao paciente, garantindo } \\
\text { que eles não transmitam o vírus. } \\
\end{array}$ & $\begin{array}{l}\text { Pesquisa realizada com base nas diretrizes } \\
\text { recentes do China National Health Comissão }\end{array}$ & $\begin{array}{l}\text { Conclui-se que medidas restritas para } \\
\text { assegurar a segurança dos profissionais de } \\
\text { saúde durante a COVID-19. }\end{array}$ \\
\hline
\end{tabular}




\begin{tabular}{|c|c|c|c|c|c|}
\hline № & Título & Autores, Ano & Objetivo & Métodos & Conclusão \\
\hline$\stackrel{n}{\sim}$ & $\begin{array}{l}\text { Utilização de aerossolterapia no contexto } \\
\text { da COVID-19 }\end{array}$ & $\begin{array}{l}\text { Andrade FMD, } \\
\text { et al.,2020 }\end{array}$ & $\begin{array}{l}\text { Fornecer informações que possam } \\
\text { servir de base para utilização de } \\
\text { aerossolterapia no contexto da } \\
\text { COVID-19. }\end{array}$ & $\begin{array}{l}\text { Estudo exploratório e explicativo, com } \\
\text { abordagem qualitativa, }\end{array}$ & $\begin{array}{l}\text { Constataram-se que a terapia inalatória é } \\
\text { usada em pacientes internados nas UTIs, } \\
\text { indicado que o adequado uso dessa via de } \\
\text { administração é fundamental para os } \\
\text { profissionais de saúde. }\end{array}$ \\
\hline$\underline{\varphi}$ & $\begin{array}{l}\text { Equipamento de proteção individual } \\
\text { (EPI) para anestesiologistas e outros } \\
\text { gestores das vias aéreas: princípios e } \\
\text { práticas durante a pandemia COVID-19 }\end{array}$ & $\begin{array}{l}\text { Lockhart SL, et } \\
\text { al., } 2020\end{array}$ & $\begin{array}{l}\text { Enfatizar os EPI's nos princípios e } \\
\text { práticas que envolvem a tomada de } \\
\text { decisão, na prevenção de } \\
\text { anestesiologistas e a outros } \\
\text { profissionais de saúde de primeira } \\
\text { linha contra a COVID-19. }\end{array}$ & $\begin{array}{l}\text { Estudo com base em observações clínicas e } \\
\text { epidemiológicas }\end{array}$ & $\begin{array}{l}\text { Torna-se apropriado medidas para minimizar o } \\
\text { estresse psicológico para profissionais de } \\
\text { saúde, EPI e testes diagnósticos suficiente, } \\
\text { salas restritas }\end{array}$ \\
\hline 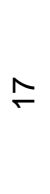 & $\begin{array}{l}\text { COVID-19: Por que a proteção de } \\
\text { trabalhadores e trabalhadoras da saúde } \\
\text { é prioritária no combate à pandemia? }\end{array}$ & $\begin{array}{l}\text { Helioterio MC, } \\
\text { et al., } 2020\end{array}$ & $\begin{array}{l}\text { Sistematizar e sumarizar aspectos } \\
\text { relativos às condições de trabalho e } \\
\text { de saúde dos profissionais da saúde } \\
\text { nessa pandemia, enfatizando a } \\
\text { situação no Brasil. }\end{array}$ & $\begin{array}{l}\text { Estudo baseado em experiências exitosas na } \\
\text { proteção do trabalho em saúde em outros } \\
\text { países e orientações para o contexto } \\
\text { brasileiro. }\end{array}$ & $\begin{array}{l}\text { Constata-se que em meio a pandemia é } \\
\text { necessário condições de trabalho melhores, } \\
\text { afim que é preciso garantir e proteger a vida } \\
\text { dos profissionais da saúde diante a COVID-19. }\end{array}$ \\
\hline$\stackrel{\infty}{-}$ & $\begin{array}{l}\text { Prevenção e controle de infecção na } \\
\text { atenção à saúde quando houver suspeita } \\
\text { de COVID-19 }\end{array}$ & $\begin{array}{l}\text { Organização } \\
\text { pan-americana } \\
\text { da saúde, } 2020\end{array}$ & $\begin{array}{l}\text { Objetivou-se compreender as } \\
\text { orientações sobre estratégias de } \\
\text { prevenção e controle de infecções } \\
\text { (PCI) quando houve suspeita de } \\
\text { COVID-19. }\end{array}$ & $\begin{array}{l}\text { Rede Global de Prevenção e Controle de } \\
\text { Infecções da OMS e outros especialistas } \\
\text { internacionais }\end{array}$ & $\begin{array}{l}\text { Conclui-se que o uso seguro dos EPls ajuda } \\
\text { na redução da disseminação dos vírus, sendo } \\
\text { que os EPIs dependem do fornecimento } \\
\text { adequado, qualificação da equipe, } \\
\text { higienização das mãos. }\end{array}$ \\
\hline$\stackrel{\sigma}{\square}$ & $\begin{array}{l}\text { Orientações para os serviços de saúde: } \\
\text { medidas que devem ser adotadas para } \\
\text { utilização de Equipamentos de Proteção } \\
\text { Individual (EPI) durante a assistência aos } \\
\text { casos suspeitos ou confirmados de } \\
\text { infecção pelo novo coronavírus (COVID- } \\
\text { 19) }\end{array}$ & BRASIL, 2020 & $\begin{array}{l}\text { Objetivou-se conhecer orientações } \\
\text { quanto ao uso de Equipamento de } \\
\text { Proteção Individual (EPI), durante a } \\
\text { assistência aos casos suspeitos ou } \\
\text { confirmados de infecção pela } \\
\text { COVID-19. }\end{array}$ & $\begin{array}{l}\text { Medidas baseadas em estudo atual e nos } \\
\text { documentos emitidos pelos órgãos oficiais: } \\
\text { Agência Nacional de Vigilância Sanitária } \\
\text { (ANVISA), Organização Mundial de Saúde } \\
\text { (OMS), Ministério da Saúde (MS) e Governo } \\
\text { do Distrito Federal (GDF). }\end{array}$ & $\begin{array}{l}\text { Adquirir conhecimento e prestar informações } \\
\text { sobre o primeiro profissional desparamenta, o } \\
\text { segundo profissional acompanha e identifica } \\
\text { se o primeiro profissional realiza seguindo a } \\
\text { técnica e a ordem seguras. }\end{array}$ \\
\hline 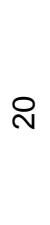 & $\begin{array}{l}\text { Protegendo os profissionais de saúde da } \\
\text { infecção por SARS-CoV-2 : indicações } \\
\text { práticas }\end{array}$ & $\begin{array}{l}\text { Ferioli M, et al., } \\
2020\end{array}$ & $\begin{array}{l}\text { Fornecer orientações com base em } \\
\text { evidências para a utilização correta } \\
\text { de "dispositivos respiratórios" na } \\
\text { emergency e proteger os } \\
\text { profissionais de saúde contra a } \\
\text { infecção por SARS-CoV-2. }\end{array}$ & $\begin{array}{l}\text { Estudo de caso-controle, com abordagem } \\
\text { diversificada, tenta responder a essas } \\
\text { questões fundamentais realizada durante a } \\
\text { epidemia de SARS em Hong Kong. }\end{array}$ & $\begin{array}{l}\text { Dado o alto risco de emissão de grandes } \\
\text { quantidades de gotículas, os procedimentos } \\
\text { de geração de aerossóis requerem maior } \\
\text { cuidado por parte dos profissionais de saúde. }\end{array}$ \\
\hline
\end{tabular}

Fonte: Soares AKT, et al.,2021. 


\section{DISCUSSÃO}

Escolheu-se com base na análise descritiva pela definição de três categorias para a discussão dos resultados, são elas: Fatores de risco de contaminação ao profissional de saúde ao cuidar de pacientes com COVID-19; Procedimentos geradores de aerossóis por COVID-19; Medidas de precaução em relação a COVID-19 na paramentação, desparamentação e descarte seguro de EPIs.

\section{Fatores de risco de contaminação ao profissional de saúde ao cuidar de pacientes com COVID-19.}

Diante o cenário que estamos vivendo da COVID-19 que apresenta um potencial risco para a sociedade e principalmente, para os trabalhadores da saúde expostos a adquirir doenças ao presta assistência a pacientes suspeitos ou confirmados, podendo esse paciente não apresenta sintomas característicos, porém disseminar o vírus. É preciso garantir a proteção aos profissionais para assegurar o cuidado no atendimento ao paciente, como também para segurar que eles não propagem o vírus (ALBAQAWI HM, et al., 2021; DURAN S, et al., 2021).

Com o intuito de impedir a transmissão do vírus do paciente para o profissional de saúde, necessitam-se cuidados essenciais, desde a internação do paciente que começa no hospital. Além de que, intervenções cirúrgicas eletivas e exames de costume precisam ser prorrogados. Pacientes que procuram a unidade hospitalar devem ganhar máscaras faciais e serem orientados a usar o tempo todo (CHEN F, et al., 2021).

Desse modo, o profissional de saúde que ficou em contato aproximado ou atendeu um paciente com COVID-19 está sob alto risco de ser contaminado. Os Centros de Controle e Prevenção de Doenças (CDC) determinam que o contato próximo na mesma ambiência com uma pessoa infectada, sem manter o afastamento de 2 metros e estar em contato direto com as excreções da pessoa contagiada por mais de 15 minutos, sendo que também os procedimentos geram aerossol sem o EPI fundamental ou está presente na sala no decorrer do procedimento sem o EPI necessário. Nesse contexto, essa transmissão de profissional para profissional é tão considerável quanto para o paciente (FRIED EA, et al., 2021; LORMANS P, et al., 2021).

As atividades de trabalho devem ser alinhadas, separando os profissionais de saúde que cuidam dos casos suspeitos ou confirmados de COVID-19, das equipes que cuidam de pacientes não acometidos por essa doença, não devem transitar de uma área de isolamento para outras áreas do serviço de saúde. Assim, reduzindo a chance de infecção cruzada entre profissionais da saúde e pacientes (SANTANA N, et al., 2020).

Diante desse risco de infecção por COVID-19, essas atividades segregadas por risco determinam o EPI adequado para o profissional de saúde, dessa forma os procedimentos de maior risco são os geradores de aerossol, como aspiração das vias aéreas, intubação e broncoscopia. Os riscos médios incluem realizar a triagem de pacientes com sintomas respiratórios, requerem um grau mais baixo de EPI. Em vista disso, assegura o uso de EPI completo, englobando óculos protetores, jaleco descartável, luvas, máscara N95 ou respirador purificador de ar alimentado (MERSHA A, et al., 2021).

Diante do exposto, requer medidas para reduzir os riscos, como: acesso e fornecimento de EPI suficiente, locais de descanso suficientes e apoio psicológico, a fim de evita uma crise que afete a saúde mental dos profissionais da saúde durante e após o COVID-19 (MOORE G, et al., 2021).

\section{Procedimentos geradores de aerossóis por COVID-19}

Os aerossóis são gerados a partir de uma ventilação de ar que colidi com a superfície de um líquido, produzindo partículas em suspensão no ar. Então, qualquer intervenção que ocasione o aumento do fluxo de ar sobre as vias do trato respiratório infectada, apresenta risco de contágio para a pessoa devido a difusão de um aerossol infectado para o meio ambiente. Os procedimentos geradores de aerossóis envolvem intubação traqueal, broncoscopia, aspiração traqueal com sistema aberto, ventilação manual antes da intubação, desconexão do paciente do ventilador, ventilação mecânica não invasiva (VNI), realização de traqueostomia, reanimação cardiopulmonar (RCP) e administração de nebulização a jato (GARCIA GPA, et al., 2021). 
Em relação a utilização de máscaras para proteção na realização de procedimentos geradores de aerossóis, são indicados tipos de máscaras faciais na filtragem de vírus respiratórios como: N95, FFP2 ou similares. Além disso, recomenda-se a utilização de máscaras cirúrgicas por pessoas doentes com propósito de reduzi as rotas de transmissão (GARCIA GPA, et al., 2021).

No contexto da COVID-19 são apresentados variados recursos para a melhoria da ventilação e oxigenação de pacientes com insuficiência respiratória de grau leve a moderada, requerendo a avaliação do risco de geração de aerossol e decorrente infecção de trabalhadores da saúde e pacientes. Vale destacar, que o processo de escolha do dispositivo de proteção reduz esse risco. Os nebulizadores a jato são recomendados a serem usados nos cuidados prestados ao paciente com COVID-19. Assim, a aplicação de aerossóis na forma de nebulização a jato para pacientes suspeitos ou confirmados, acometidos por essa doença, podem aumentar o potencial risco de infecção viral entre profissionais, pacientes e demais pessoas envolvidas (ROSE P, et al., 2020).

A propagação de doenças por aerossol ocorre por gotículas grandes e pequenas ou pela suspensão de partículas no ar. Desse modo, as secreções respiratórias são difundidas e transmitem doenças quando um paciente fala, espirra, tosse ou quando são realizados procedimentos geradores de aerossol, aumentando 0 risco de contaminação do profissional de saúde. Estima-se que o período de tempo que as partículas são difundidas pelo ar, é determinada por vários fatores como: a quantidade de trocas de ar por hora do quarto do paciente, a condição de a sala ter pressão negativa ou positiva estabelecera a passagem de saída das partículas propagadas pelo ar (ASSUNÇÃO AA, et al., 2020).

Nesse cenário, a infecção pelo SARS-CoV-2 pode continuar acessível em aerossóis por horas e em superfícies por dias, permitindo a propagação do aerossol no ambiente. Portanto, conclui-se que o cansaço por excesso de trabalho e exaustão profissional, são uma grande preocupação, assim como o fato de se infectar em virtude a exposições de alto risco como (intubação imediata ou procedimentos geradores de aerossol) e a carência de EPI adequado para os profissionais de saúde (ARANAZ JMA, et al., 2020).

\section{Medidas de precaução em relação à COVID-19 na paramentação, desparamentação e descarte seguro de EPIs}

O panorama atual representa um risco aos trabalhadores de saúde constantemente expostos a infecção por COVID-19, o que acarreta em alta predisposição a adoecer. Assim, diante esse risco, deve ser utilizado em qualquer procedimento, intervenção ou atendimento, o uso seguro de EPI na paramentação e desparamentação, como também o descarte correto desses equipamentos com o intuito de proteger e evita contaminações (OLIVEIRA AC, et al., 2020; CHANG D, et al., 2020).

Nesse sentido, temos na linha de frente profissionais expostos ao coronavírus e em contato direto com pessoas como: enfermeiros(as), técnicos(as) de enfermagem, médicos(as), fisioterapeutas, equipe de limpeza, seguranças e recepcionistas de serviços de saúde, dentre outros. As infecções estão relacionadas ao uso incorreto das medidas de precaução, carência de EPI, pessoas infectadas e assintomáticas que tiveram contato com a equipe (ANDRADE FMD, et al., 2020; LOCKHART SL, et al., 2020).

No que diz a respeito a importância de EPI, são essenciais para proteção dos trabalhadores de saúde, sendo responsabilidade do empregador a efetivação de uso, conservação e descarte. Desse modo, os tipos de EPIs fundamentais são pautados nas atividades realizadas e no risco biológico, sendo disponibilizados para esse uso: gorro, protetor facial ou óculos de proteção, máscara cirúrgica ou similar, avental impermeável de mangas longas e luvas de procedimentos. Dentre os critérios de prevenção e controle de infecção (PCl) para evita a contaminação, envolvem: realiza a triagem, isolando pacientes com suspeita de COVID-19 e cumprimento das precauções-padrões para todos (HELIOTERIO MC, et al., 2020; OPAS, 2020).

As precauções-padrões compreendem a higienização das mãos e respiratória, a utilização de EPIs de acordo com o risco que será exposto, roupa de cama adequada, higienização do ambiente e esterilização de equipamentos usados nos cuidados concedidos aos pacientes. Devem ser orientadas medidas de higiene 
respiratória para o paciente, como ao tossir ou espirrar usa o cotovelo, manter o nariz e boca cobertos, disponibiliza máscara cirúrgica para pacientes com suspeita de COVID-19, enquanto os trabalhadores da saúde devem utilizar com base na OMS os 5 momentos para higienização das mãos antes e após contato com o paciente, auxiliando na redução da disseminação de patógenos (OPAS, 2020).

É importante destacar que os profissionais de saúde saibam das orientações do uso de EPIs em relação aos cuidados prestados aos pacientes suspeitos ou confirmados de infecção por coronavírus, devem manter a ventilação para amplia a troca de ar nos ambientes (em casos de procedimento geradores de aerossol, a ventilação deve ter fluxo de ar natural ou em quartos com pressão negativa), realiza a limpeza e desinfecção das superfícies a quais o paciente teve contato com álcool $70 \%$, hipoclorito de sódio $1 \%$ ou a base de fenóis e iodóforos, EPIs de uso pessoal e distanciamento mínimo de 1 metro entre as pessoas (BRASIL, 2020).

Tendo em vista o uso prolongado de máscara para cuidar a mais de um paciente, sem retirá-la, tem sido uma estratégia praticada quando diversos pacientes são contaminados pela COVID-19. Nos casos de a máscara estive com vedação funcional danificada, úmida ou com secreções, deve ser descartada e trocada imediatamente, sendo considerável usar barreiras adicionais que não permita o contágio, de preferência o protetor ocular ou máscara cirúrgica sobre a N95 ou similar. Recomenda-se não usar barba e maquiagem que ocasionam contaminação ou dificultam a vedação de máscaras no rosto. $O$ uso de avental é exclusivo por profissional, deve ser descartado em lixo infectante ou em suporte com saco hamper, quando estive com secreções, molhado ou danificado (BRASIL, 2020).

Medidas devem ser recomendadas para paramentação e desparamentação dos EPIs para os profissionais de saúde diante a infecção por COVID-19, começando por saber os materiais necessários para se prevenir, que são: Gorro ou touca, capote ou avental, máscara cirúrgica ou N95/PFF2 ou semelhante, protetor facial ou óculos de proteção e luvas de procedimento (BRASIL, 2020).

Dentro dessa abordagem, são seguidos uma ordem de paramentação dos profissionais ao atender pacientes com a COVID-19, que são: Higieniza as mãos com água e sabão ou solução alcoólica a $70 \%$, coloque o gorro, coloque o avental impermeável ou descartável, coloque a máscara cirúrgica ou nos procedimentos geradores de aerossol, coloca a máscara N95,coloque protetor facial ou óculos, higienize as mãos e calçar as luvas de procedimento e ao desparamenta a ordem, são as seguintes: Remova as luvas de procedimento, evitando tocar o lado externo, pois estão contaminadas, remova o avental, abrir os laços do pescoço e cintura e solte-os, remova protetor facial pela lateral ou hastes, remova a máscara e acondicione em um saco ou envelope de papel, remova o gorro, higieniza as mãos, coloca a luva de procedimento para realiza a desinfecção dos óculos de proteção, remova as luvas e higieniza as mãos; Na retirada de um e outro EPI, tem que higieniza as mãos (BRASIL, 2020).

Em vista disso, os profissionais de saúde que atuam em um ambiente de alto risco estão expostos ao vírus, sendo que o uso de barreiras físicas pode reduzir o risco de contaminação. Portanto, saber sobre o uso das medidas de precaução na paramentação, desparamentação e o descarte seguros dos EPIs são fundamentais para proteção dos envolvidos no processo de cuidar de pacientes com suspeita ou confirmado para COVID-19 (FERIOLI M, et al., 2020).

\section{CONSIDERAÇÕES FINAIS}

Considerando o exposto e o atual cenário global da saúde, os profissionais de saúde estão expostos a um alto risco de contaminação por COVID-19 ao realizar atendimento, como também em procedimentos geradores de aerossol e na utilização de EPIs. Logo, diante as repercussões da covid-19 para diminuir a transmissão por aerossóis e infecções por áreas contaminadas é necessárias orientações a equipe em relação a proteção individual com conhecimento teórico, treinamento ao se paramentar, desparamentar e descarte seguros de EPIs, fornecimentos de EPI em quantidade suficientes, com o intuito de reduzir a contaminação por coronavírus entre os trabalhadores da área da saúde, através da educação continuada e treinamentos. 


\section{REFERÊNCIAS}

1. ALBAQAWI HM, et al. Risk assessment and management among frontline nurses in the context of the COVID-19 virus in the northern region of the Kingdom of Saudi Arabia. Applied Nursing Research, 2021; 58: e151410.

2. ANDRADE FMD, et al. Utilização de aerossolterapia no contexto da COVID-19. ASSOBRAFIR Ciência, 2020; 11(1): 153-160.

3. ARANAZ JMA, et al. Mascarillas como equipo de protección individual durante la pandemia de COVID-19: cómo, cuándo y cuáles deben utilizarse. J Healthc Qual. Res, 2020; 35(4): 245-252.

4. ARAÚJO BCL, et al. COVID-19 e disfagia: guia prático para atendimento hospitalar seguro - número 1. Audiol Commum Res, 2020; 25: e2384.

5. ASSUNÇÃO AA, et al. COVID-19: Limits on the implementation of personal protective equipments recommended to health care professionals. Health Sciences, 2020; 00: 1-16.

6. ATZARODT CL, et al. A Guide to COVID-19: a global pandemic caused by the novel coronavirus SARS-CoV-2. The FEBS Journal, 2020; 287: 3633-3650.

7. BRASIL. Manual do Ministérios de Saúde. 2020. Disponível em:http://www.saude.df.gov.br/wpconteudo/uploads/2020/02/Nota_Tecnica_EPIs_GRSS_atualizada.pdf . Acessado em: 26 de abril 2021.

8. CHANG D, et al. Protecting health-care workers from subclinical coronavirus infection. Lancet Respir Med, 2020; 8(3): e13.

9. CHEN F, et al. Dispatched nurses' experience of wearing full gear personal protective equipment to care for COVID19 patients in China - A descriptive qualitative study. J Clin Nurs, 2021; 00: 1-14.

10. DURAN S, et al. Factors Affecting Nurses' Professional Commitment During the COVID-19 Pandemic: A CrossSectional Study. J Nurs Manag, 2021; 00: 1-10.

11. FERIOLI M, et al. Protecting healthcare workers from SARS-CoV-2 infection: practical indications. Eur Respir Rev, 2020; 29(55): 200068.

12. FRIED EA, et al. Barrier Devices, Intubation, and Aerosol Mitigation Strategies: Personal Protective Equipment in the Time of Coronavirus Disease 2019. Anesth Analg, 2021; 132(1): 38-45.

13. GARCIA GPA, et al. Utilização de equipamentos de proteção individual para atendimento de pacientes com COVID19: revisão de escopo. Rev Gaúcha Enferm, 2021; 42(esp): e20200150.

14. HELIOTERIO MC, et al. COVID-19: Por que a proteção de trabalhadores e trabalhadoras da saúde é prioritária no combate à pandemia? Trab. Educ. Saúde, 2020; 18(3): e00289121.

15. KIM UJ, et al. Air and Environmental Contamination Caused by COVID-19 Patients: a Multi-Center Study. J Korean Med Sci, 2020; 35(37): e332.

16. LOCKHART SL, et al. Personal protective equipment (PPE) for both anesthesiologists and other airway managers: principles and practice during the COVID-19 pandemic. Can J Anaesth, 2020; 67(8): 1005-1015.

17. LORMANS $P$, et al. COVID-19 acquisition risk among ICU nursing staff with patient-driven use of aerosol-generating respiratory procedures and optimal use of personal protective equipment. Intensive and Critical Care Nursing, 2021; 63: e102993.

18. MACHADO WCA, et al. COVID-19 in the paramentation movements of dressing and disposing of nurses: nightingale, the pioneer, was reasoned. Research, Society and Development, 2020; 9(7): 1-23, e741974731.

19. MARQUES LC, et al. COVID-19: cuidados de enfermagem para segurança no atendimento de serviço pré-hospitalar móvel. Texto \& Contexto Enfer, 2020; 29: e20200119.

20. MERSHA A, et al. Health professionals practice and associated factors towards precautionary measures for COVID19 pandemic in public health facilities of Gamo zone, southern Ethiopia: A cross-sectional study. Plos One, 2021; 16(3): e0248272.

21. MOORE G, et al. Detection of SARS-CoV-2 within the healthcare environment: a multi-centre study conducted during the first wave of the COVID-19 outbreak in England. J Hosp Infect, 2021; 108: 189-196.

22. MORRELL ALG, et al. Manejo intraoperatório em cirurgia laparoscópica ou robótica para minimizar a dispersão de aerossóis: Adaptações ao contexto da pandemia por COVID-19. Rev. Col. Bras. Cir, 2020; 47: e20202558.

23. OLIVEIRA AC, et al. What has the COVID-19 pandemic taught us about adopting preventive measures?. Texto Contexto - Enferm, 2020; 29: e20200106.

24. OLIVEIRA HC, et al. Personal Protective Equipment in the coronavirus pandemic: training with Rapid Cycle Deliberate Practice. Rev. Bras. Enferm, 2020; 73(2): e20200303.

25. ORGANIZAÇÃO PAN-AMERICANA DA SAÚDE. Prevenção e controle de infecção na atenção à saúde quando houver suspeita de COVID-19: orientação provisória. 2020.

26. ROSE $\mathrm{P}$, et al. A comparison of droplet and contact contamination using 3 simulated barrier techniques for COVID-19 intubation: a quality assurance study. CMAJ Open, 2020; 8(3): E554-E559.

27. SANTANA N, et al. Segurança dos profissionais de saúde no enfrentamento do novo coronavírus no Brasil. Esc. Anna Nery, 2020; 24(spe): e20200241.

28. SOMMERSTEIN R, et al. Risk of SARS-CoV-2 transmission by aerosols, the rational use of masks, and protection of healthcare workers from COVID-19. Antimicrob Resist Infect Control, 2020; 9(100): 1-8.

29. STRUYF T, et al. Signs and symptoms to determine if a patient presenting in primary care or hospital outpatient settings has COVID-19 disease. Conchrane Library, 2020; 7: CD013665. 